\title{
Differential Diagnosis in Neurology and Neurosurgery: A Clinician's Pocket Guide
}

\author{
Eugen Boltshauser ${ }^{1}$ \\ ${ }^{1}$ Department of Pediatric Neurology, University Children's Hospital, \\ Zurich, Switzerland
}

Neuropediatrics 2019;50:271-272.

Differential Diagnosis in Neurology and Neurosurgery: A Clinician's Pocket Guide.

S. A. Tsementzis. 2nd Edition. Stuttgart: Thieme Publishers; 2019 (698 pages, 417 illustrations). ISBN 978-3-13-2417182. EUR ca 55.00 (e-book: eISBN 978-3-13-241719-9)

Is it appropriate to review a book on the differential diagnosis in neurology and neurosurgery in a pediatric neurology journal? The syllabus of the European Paediatric Neurology Society strongly recommends an elective training period in (adult) neurology for trainees in pediatric neurology, and in some countries, this is required (for 6 months or more). Hence, such a pocket guide may be helpful as a quick reference for trainees, as well as for graduated colleagues. Needless to underline that pediatric neurology and neurology are overlapping fields.

The author is a Professor and the Chairman emeritus of neurosurgery, Neurosurgical Institute at University of Ioannina, Greece. This expanded second edition follows the first one after 15 years, it was updated, complemented by chapters on neuroimaging, and on developmental and acquired pediatric disorders, and it is now electronically accessible via a personal code. The volume is organized in the following 15 chapters (major headings):

- Epidemiological Characteristics of Neurological Diseases

- Neuroradiology

- Developmental and Acquired Anomalies and Pediatric Disorders

- Cranial Nerve Disorders
Address for correspondence Prof. em. Eugen Boltshauser, Department of Pediatric Neurology, University Children's Hospital, Steinwiesstrasse 75, 8032 Zürich, Switzerland (e-mail: eugen.boltshauser@bluewin.ch).

- Neuro-Ophthalmology

- Intracranial Tumors

- Demyelinating Diseases and Brain Atrophy

- Cerebrovascular Disease (Stroke)

- Spinal Disorders

- Peripheral Nerve Disorders

- Movement Disorders

- Neurotrauma

- Infections of the Central Nervous System

- Pain

- Neurorehabilitation.

"The aim of this book is to provide assistance with differential diagnosis in neurological and neurosurgical disease, it is not intended for use on its own, as it is not a complete textbook" (quote from the preface). The book provides a guide to the differentiation of over 230 symptoms, physical and radiological sings, and other abnormal findings in the form of "checklists", photos, diagrams, and compacted information of disorders (with paragraphs on signs and symptoms, diagnosis, differential diagnosis, investigations, etc.). Pediatric hints about posterior fossa cysts, intraspinal cysts, torticollis in children, pediatric coma scale, back pain in children, and adolescents, etc., are mentioned.

In my view, the author has reached his aim of providing a quick reference for daily practice (or as an examination preparation guide). The print quality is excellent; the value for money is favorable. published online

May 2, 2019 (c) 2019 Georg Thieme Verlag KG Stuttgart · New York
DOI https://doi.org/ 10.1055/s-0039-1688766. ISSN 0174-304X. 
